\title{
Timing, causes, predictors and prognosis of switching from peritoneal dialysis to hemodialysis: a prospective study
} Bernard G Jaar*1,2,3, Laura C Plantinga ${ }^{2}$, Deidra C Crews ${ }^{1,2}$, Nancy E Fink ${ }^{1,2}$, Nasser Hebah ${ }^{4}$, Josef Coresh ${ }^{1,2}$, Alan S Kliger ${ }^{5}$ and Neil R Powe ${ }^{1,2,6}$

Address: ${ }^{1}$ Department of Medicine, Johns Hopkins University School of Medicine, Baltimore, MD, USA, ${ }^{2}$ Department of Epidemiology, Johns Hopkins Bloomberg School of Public Health, Baltimore, MD, USA, ${ }^{3}$ Nephrology Center of Maryland, Baltimore, Maryland, USA, ${ }^{4}$ Dialysis Clinic, Inc., Nashville, TN, USA, ${ }^{5}$ Department of Medicine, Hospital of St. Raphael, New Haven, CT, USA and ${ }^{6}$ Department of Health Policy and Management, Johns Hopkins Bloomberg School of Public Health, Baltimore, MD, USA

Email: Bernard G Jaar* - bjaar@jhmi.edu; Laura C Plantinga - lplantin@jhsph.edu; Deidra C Crews - dcrews1@jhmi.edu; Nancy E Fink - nfink@jhsph.edu; Nasser Hebah - nasser.hebah@dciinc.org; Josef Coresh - coresh@jhu.edu; Alan S Kliger - AKliger@srhs.org; Neil R Powe-npowe@jhmi.edu

* Corresponding author

Published: 6 February 2009

BMC Nephrology 2009, 10:3 doi:10.1 186/1471-2369-10-3
Received: 7 November 2008

Accepted: 6 February 2009

This article is available from: http://www.biomedcentral.com/I47I-2369//0/3

(c) 2009 Jaar et al; licensee BioMed Central Ltd.

This is an Open Access article distributed under the terms of the Creative Commons Attribution License (http://creativecommons.org/licenses/by/2.0), which permits unrestricted use, distribution, and reproduction in any medium, provided the original work is properly cited.

\begin{abstract}
Background: The use of peritoneal dialysis (PD) has declined in the United States over the past decade and technique failure is also reportedly higher in PD compared to hemodialysis (HD), but there are little data in the United States addressing the factors and outcomes associated with switching modalities from PD to HD.
\end{abstract}

Methods: In a prospective cohort study of 262 PD patients enrolled from 28 peritoneal dialysis clinics in 13 U.S. states, we examined potential predictors of switching from PD to HD (including demographics, clinical factors, and laboratory values) and the association of switching with mortality. Cox proportional hazards regression was used to assess relative hazards $(\mathrm{RH})$ of switching and of mortality in PD patients who switched to HD.

Results: Among 262 PD patients, $24.8 \%$ switched to HD; with more than $70 \%$ switching within the first 2 years. Infectious peritonitis was the leading cause of switching. Patients of black race and with higher body mass index were significantly more likely to switch from PD to $\mathrm{HD}, \mathrm{RH}(95 \% \mathrm{Cl})$ of $5.0 \mathrm{I}(\mathrm{I} .15-2 \mathrm{I} .8)$ for black versus white and 1.09 (I.03-1.16) per $\mathrm{I} \mathrm{kg} / \mathrm{m}^{2}$ increase in BMl, respectively. There was no difference in survival between switchers and non-switchers, $\mathrm{RH}(95 \%$ $\mathrm{Cl})$ of $0.89(0.4 \mathrm{I}-\mathrm{I} .93)$.

Conclusion: Switching from PD to HD occurs early and the rate is high, threatening long-term viability of PD programs. Several patient characteristics were associated with the risk of switching. However, there was no survival difference between switchers and non-switchers, reassuring providers and patients that PD technique failure is not necessarily associated with poor prognosis.

\section{Background}

Hemodialysis (HD) and peritoneal dialysis (PD) represent the two main modalities for renal replacement ther- apy. PD is typically considered a home dialysis program, as the patients have the autonomy to perform the treatment in their home environment, whereas most HD 
patients must travel to a dialysis center, usually three times a week, to receive their treatment. Despite the potential benefit of PD compared to HD in quality of life [1] and associated patient satisfaction [2], prevalent use of PD has declined in the United States since 1994-1995, by as much as $67 \%$ in some regions of the country [3]. The number of incident end-stage renal disease (ESRD) patients initiating PD has also declined over the same time period [3]. This decline in PD utilization has been observed not only in the United States but also in Europe and elsewhere $[3,4]$. Technique failure is known to be much higher in PD than HD patients [5-7] and this likely plays a significant role in the declining prevalence of PD utilization. Peritonitis has been described as one of the leading causes of transfer from PD to HD [7-9] and only a small group of patients can return to PD after severe peritonitis and Tenckhoff catheter removal [10].

Over the past decade, very few studies in the United Sates have analyzed both the cause of switching from PD to HD and the timing of this switching process after initiation of PD. Further, there is a paucity of studies, particularly in the United States, aimed at identifying risk factors associated with switching from PD to HD in ESRD patients and subsequent patient outcomes. The purpose of this study was to determine patient characteristics associated with the risk of switching from PD to HD and to assess patient survival following dialysis modality switches in a cohort of incident peritoneal dialysis patients.

\section{Methods}

\section{Study design and research population}

The Choices for Healthy Outcomes in Caring for ESRD (CHOICE) is a national prospective cohort study of incident dialysis patients [11]. For the purposes of this study, we limited our sample to 262 white and black peritoneal dialysis patients from the CHOICE cohort. From October 1995 to June 1998, participants from 13 states were enrolled at 28 clinics offering peritoneal dialysis and associated with Dialysis Clinic, Inc. (Nashville, TN; $n=178$ ), New Haven CAPD (New Haven, CT; $n=82$ ) or St. Raphael's Hospital (New Haven, CT; $n=2$ ). Eligibility criteria for enrollment included ability to provide informed consent for participation, age older than 17 years, and ability to speak English or Spanish. Median time from start of peritoneal dialysis to enrollment was 29 days, with $99 \%$ enrolling within 4 months of initiating dialysis. All participants gave written informed consent after Institutional Review Boards for Johns Hopkins University and clinical centers approved the study protocol.

\section{Data collection}

\section{Dialysis modality and switching}

Dialysis modality was defined as the modality in use at 4 weeks after enrollment in the study (an average of 10 weeks after starting dialysis). This information was obtained from clinic records. The initial dialysis modality information was abstracted from the Centers for Medicare and Medicaid Services (CMS) ESRD Medical Evidence Report (Form 2728). All forms of PD (continuous ambulatory PD, continuous cycling PD and intermittent cycling PD) were combined as a single category. Patients were considered to have switched to hemodialysis (HD) when they changed from PD to HD and remained on the latter modality for at least 30 days. Causes of switch from PD to HD were ascertained from comprehensive chart review. Patients were censored for time to switch at transplantation, loss to follow-up, death, or last date of follow-up (December 31, 2004).

\section{Demographic and clinical data}

All patients completed a baseline self-report questionnaire and provided information on demographics, health behaviors, work history, medical history, and distance to dialysis unit. Late referral was defined as $<4$ months between first nephrologist evaluation and start of dialysis, as described previously [12]. Residual urine output, obtained from the patient baseline self-report questionnaire, was defined as the ability to make at least $250 \mathrm{cc}$ (1 cup) of urine per day. Body mass index (BMI) was calculated using the standard formula weight (in $\mathrm{kg}$ )/[height (in meters) $]^{2}$, based on the height and weight reported on the 2728 form. Comorbidity, referring to medical conditions other than the primary disease itself and the severity of those conditions, was assessed using the ICED, a medical record-derived index that has been demonstrated to predict death in dialysis populations $[13,14]$. ICED scores range from 0 to 3 , with 3 as the highest severity level. It is a measure of both the presence and severity of comorbid conditions, as described previously. Baseline data for routine patient care were available for the following laboratory values: serum albumin, hemoglobin, total cholesterol, and serum creatinine. High-sensitivity C-reactive protein (CRP) level was assessed at a median of 5.0 months from dialysis initiation, using a colorimetric competitive enzyme-linked immunosorbent assay (coefficient of variation, 8.9\%). Glomerular filtration rate (GFR) before dialysis initiation was estimated by the six-variable Modification of Diet in Renal Disease (MDRD) equation using serum creatinine obtained from the CMS Form 2728 [15].

\section{Mortality ascertainment}

Mortality information was ascertained from clinic report, medical records, National Death Index and CMS (death notification forms and Social Security records). Follow-up for mortality continued until death $(n=88)$, transplantation $(n=69)$, loss to follow-up [when patients left the study or study clinic $(n=97)]$, or the last follow-up date of December 31, $2004(n=8)$. Patients were followed for 
mortality for up to 8.9 years (average follow-up, 2 years). In sensitivity analyses, we also assessed mortality without loss to follow-up, by including deaths tracked by passive follow-up through death certificates of patients who left the study or the study clinic.

\section{Statistical analysis}

We compared characteristics of patients who switched (switchers) to hemodialysis with those patients who remained on PD (non-switchers) by using $t$ tests for continuous variables and Pearson's $\chi^{2}$ tests for categorical variables. CRP was log-transformed to reduce skewness of distribution.

We used time-dependent Cox proportional hazards models to assess the risk factors for switching by analyzing the time to first switch from peritoneal dialysis to hemodialysis. Time-dependent analyses were performed to reduce lead-time bias, since, by definition, those who switched modality had to survive at least until the switch. In these analyses, all patients started as non-switchers, and if the patient switched the patient then became a switcher in the analyses. In multivariable models, we adjusted for potential confounders, including variables associated with both baseline modality and switching. We also used Cox proportional hazards models to assess the mortality risk of patients on peritoneal dialysis who switched to hemodialysis versus patients who remained on peritoneal dialysis, independent of differences in demographics (e.g., age, race, and employment status), clinical factors (e.g., ICED comorbidity score, diabetes mellitus status, history of cardiovascular disease, body mass index, and baseline residual urine output), and laboratory values (e.g., serum albumin and creatinine).

We also examined whether the mortality risk was similar by year of follow-up and among persons with different clinical characteristics by performing Cox proportional hazards analyses in subpopulations based on survival time, diabetes mellitus status, history of cardiovascular disease, baseline residual urine output and baseline serum albumin $(<3.5 \mathrm{~g} / \mathrm{dl}$ versus $\geq 3.5 \mathrm{~g} / \mathrm{dl})$. We formally tested for interactions that had been found to be significant in previous studies by including interaction terms and testing their statistical significance in the full population models. Furthermore, we tested for and found no deviations from the proportional hazards assumption by examining the global test of Schoenfeld residuals, both overall and within each follow-up year. Finally, we accounted for possible dependence of observations within clinics [16] by performing fixed-effects modeling clustered on the dialysis clinic. Statistical analyses were performed using Stata version 8.2 (StataCorp, College Station, TX).

\section{Results}

\section{Patient characteristics}

Among the 262 peritoneal dialysis patients, $24.8 \%$ switched to hemodialysis during the study period. PD patients who switched to HD had higher BMI and serum creatinine at baseline and were less likely to be white and to have residual urine output at both baseline and 1 year of follow-up. There were no other demographic, clinical or laboratory differences between PD switchers and nonswitchers at baseline (Table 1).

\section{Causes of switching and time to switch from peritoneal dialysis to hemodialysis}

More than $40 \%$ of the PD patients who switched to HD did so within the first year after starting PD and more than $70 \%$ within the first two years (Figure 1). Infections (peritonitis and catheter-related) (36.9\%) were the leading cause of switching from PD to HD, followed by cardiovascular (fluid overload) causes (18.5\%). Less common causes of switching from PD to HD included abdominal surgery, pancreatitis/malnutrition, decreased mental capacity and abdominal wall defect (Table 2). Infectious peritonitis was a leading cause of switch from PD to HD during most of the follow-up period, whereas cardiovascular/fluid overload as a cause of switch became more dominant after the first year on peritoneal dialysis (Figure 2). Patients who switched due to infectious peritonitis versus any other cause were younger (47.1 versus 54.7 years, $P=0.02)$ and less likely to be white $(52.2 \%$ versus $83.3 \%$, $P=0.007)$; otherwise there were no other significant differences between these patients.

\section{Risk factors associated with switching from peritoneal dialysis to hemodialysis}

In the unadjusted model, PD patients of black race were nearly 3 times more likely than white PD patients to switch from PD to HD; this risk became stronger after adjustment (Table 3). Patients who were less educated were 2.5 times more likely to switch from PD to HD, compared to patients who had at least a high school education; however, this association was not statistically significant. Patients living 30 miles or more from the dialysis clinic were 58\% less likely to switch from PD to HD compared to patients living fewer than 30 miles from the dialysis clinic; but this association was marginally statistically significant. In both unadjusted and adjusted analyses, the risk of switching from PD to HD significantly increased by about $10 \%$ for each $1 \mathrm{~kg} / \mathrm{m}^{2}$ higher BMI. In the unadjusted analysis, for each $1 \mathrm{mg} / \mathrm{dl}$ higher serum baseline creatinine, there was a $13 \%$ increased risk of switching from PD to HD; however, this relationship was no longer statistically significant after adjustment. We found no significant risk of switching from PD to HD by age, employment status, or diabetes mellitus status (Table 3). Similarly, in sensitivity analyses, Index of Coexistent 
Table I: Patient characteristics by peritoneal dialysis switching status

\begin{tabular}{|c|c|c|c|c|}
\hline Characteristic & $\mathbf{N}$ & Non-switchers & Switchers & $\mathbf{P}$ \\
\hline Total & 262 & 197 (75.2\%) & $65(24.8 \%)$ & -- \\
\hline \multicolumn{5}{|l|}{ Demographic } \\
\hline Mean age at enrollment, years & 262 & $54.7 \pm 15.4$ & $52.0 \pm 13.0$ & 0.202 \\
\hline Sex (\% female) & 262 & 42.1 & 47.7 & 0.433 \\
\hline Race (\% white) & 262 & 83.8 & 72.3 & 0.042 \\
\hline Education (\% high school graduate) & 225 & 84.2 & 75.4 & 0.131 \\
\hline Employment (\% working) & 262 & 28.4 & 20.0 & 0.181 \\
\hline Marital Status (\% married) & 238 & 68.9 & 62.3 & 0.341 \\
\hline Distance from clinic ( $\%>30$ miles) & 216 & 28.3 & 28.1 & 0.973 \\
\hline \multicolumn{5}{|l|}{ Clinical } \\
\hline Smoking status (\% ever smoker) & 227 & 61.5 & 60.7 & 0.914 \\
\hline Modality at start, from 2728 (\% HD) & 256 & 7.8 & 9.4 & 0.693 \\
\hline ICED score (\%) & 262 & & & 0.848 \\
\hline$\leq 1$ & & 50.3 & 46.2 & \\
\hline 2 & & 25.4 & 27.7 & \\
\hline 3 & & 24.4 & 26.2 & \\
\hline Diabetes (\% diabetic) & 262 & 49.2 & 58.5 & 0.197 \\
\hline History of CVD (\% positive) & 262 & 52.3 & 41.5 & 0.133 \\
\hline History of CHD (\% positive) & 262 & 41.1 & 32.3 & 0.207 \\
\hline History of CHF (\% positive) & 262 & 40.6 & 29.2 & 0.101 \\
\hline Primary cause of renal failure (\%) & 259 & & & 0.341 \\
\hline Diabetes mellitus & & 44.8 & 53.9 & \\
\hline Hypertension & & 10.8 & 6.2 & \\
\hline Glomerulonephritis & & 44.3 & 40.0 & \\
\hline Late referral (\% <4 months) & 198 & 21.7 & 16.4 & 0.404 \\
\hline $\mathrm{BMI}, \mathrm{kg} / \mathrm{m}^{2}$ & 245 & $25.9 \pm 5.6$ & $28.2 \pm 6.0$ & 0.006 \\
\hline Residual urine output (\%) & 186 & & & 0.018 \\
\hline Not at baseline or follow-up at I year & & 14.6 & 19.6 & \\
\hline
\end{tabular}


Table I: Patient characteristics by peritoneal dialysis switching status (Continued)

\begin{tabular}{|c|c|c|c|c|}
\hline At baseline but not at follow-up at I year & & 17.7 & 33.9 & \\
\hline At baseline and at follow-up at I year & & 67.7 & 46.4 & \\
\hline \multicolumn{5}{|l|}{ Laboratory } \\
\hline Mean baseline albumin, $g / d l$ & 248 & $3.57 \pm 0.44$ & $3.64 \pm 0.38$ & 0.316 \\
\hline Mean baseline hemoglobin, g/dl & 246 & $11.3 \pm 1.5$ & $11.3 \pm 1.5$ & 0.766 \\
\hline Median CRP (IQR), $\mu \mathrm{g} / \mathrm{dl}$ & 162 & $2.6(1.1-6.2)$ & $3.5(1.6-5.7)$ & 0.638 \\
\hline Baseline creatinine, $\mathrm{g} / \mathrm{dl}$ & 252 & $7.08 \pm 2.66$ & $7.94 \pm 2.63$ & 0.029 \\
\hline Baseline cholesterol, mg/dl & 220 & $207 \pm 53$ & $210 \pm 57$ & 0.746 \\
\hline Baseline GFR, cc/minute/l.73 $\mathrm{m}^{2}$ & 254 & $10.5 \pm 0.26$ & $10.3 \pm 0.45$ & 0.721 \\
\hline
\end{tabular}

*By t-test (continuous variables) or $\chi^{2}$ test (categorical variables)

Disease (ICED) and residual urine output were not associated with the risk of switching from PD to HD (data not shown).

\section{Mortality risk associated with switching from peritoneal dialysis to hemodialysis}

The mortality rate per 100 patient-years was 18.5 for PD non-switchers versus 13.5 for PD patients who switched to HD (Table 4). The cumulative mortality did not differ between switchers and non-switchers (Figure 3). In the unadjusted analyses, switchers had a $6 \%$ decreased risk of death but the association was not statistically significant. After adjustment for demographics, clinical factors, and laboratory values, there was an $11 \%$ decreased risk of death in PD switchers compared to non-switchers but the results were not statistically significant (Table 4).

Table 2: Causes of switching from peritoneal dialysis to hemodialysis

\begin{tabular}{lc}
\hline Causes of Switching & $\begin{array}{c}\text { Number (\%) } \\
\mathbf{N}=65\end{array}$ \\
\hline Infection (peritonitis and catheter-related) & $24(36.9 \%)$ \\
\hline Cardiovascular (fluid overload) & $12(18.5 \%)$ \\
\hline Abdominal surgery & $8(12.3 \%)$ \\
\hline Pancreatitis/malnutrition & $7(10.8 \%)$ \\
\hline Decreased mental capacity & $2(3.1 \%)$ \\
\hline Abdominal wall defect & $1(1.6 \%)$ \\
\hline Unknown & $11(16.9 \%)$ \\
\hline
\end{tabular}

In our sensitivity analyses, we found no significant decreased risk of death for PD switchers versus nonswitchers by year of follow-up ( $1^{\text {st }}$ and $2^{\text {nd }}$ years) or after stratification by diabetes mellitus status, history of cardiovascular disease, baseline residual urine output, and baseline serum albumin $(<3.5 \mathrm{~g} / \mathrm{dl}$ versus $\geq 3.5 \mathrm{~g} / \mathrm{dl}$ ) (data not shown). Additionally, when we examined the effects of including passive follow-up in our mortality data, results were similar and non-statistically significant (data not shown).

\section{Discussion}

This prospective cohort study of incident PD patients showed that about $25 \%$ of patients switched to HD over time, with more than $70 \%$ of the switching occurring within the first 2 years of treatment. Peritonitis was the leading cause of this modality change. In this U.S. prospective cohort study, the leading independent predictors of dialysis modality switching from PD to HD were black race and higher BMI. Importantly, there was no statistically significant survival difference between PD patients who switched to HD compared to those who remained on PD.

At the end of 2005 , only about $7.6 \%$ of U.S. dialysis patients were treated with $\mathrm{PD}$, and this prevalence has been declining since the mid-1990s [3]. One of the factors certainly contributing to this low PD prevalence remains the unacceptable high transfer rate from PD to HD described in several cohorts [7,17-22]. In an older Italian study with long follow-up, $18 \%$ of PD patients switched modality, as compared to $2.8 \%$ of the HD patients [7]. In our U.S. incident cohort, this switching rate was $25 \%$ for PD patients switching to HD, compared to $5 \%$ for HD patients switching to PD [18]. In the Netherlands Cooper- 


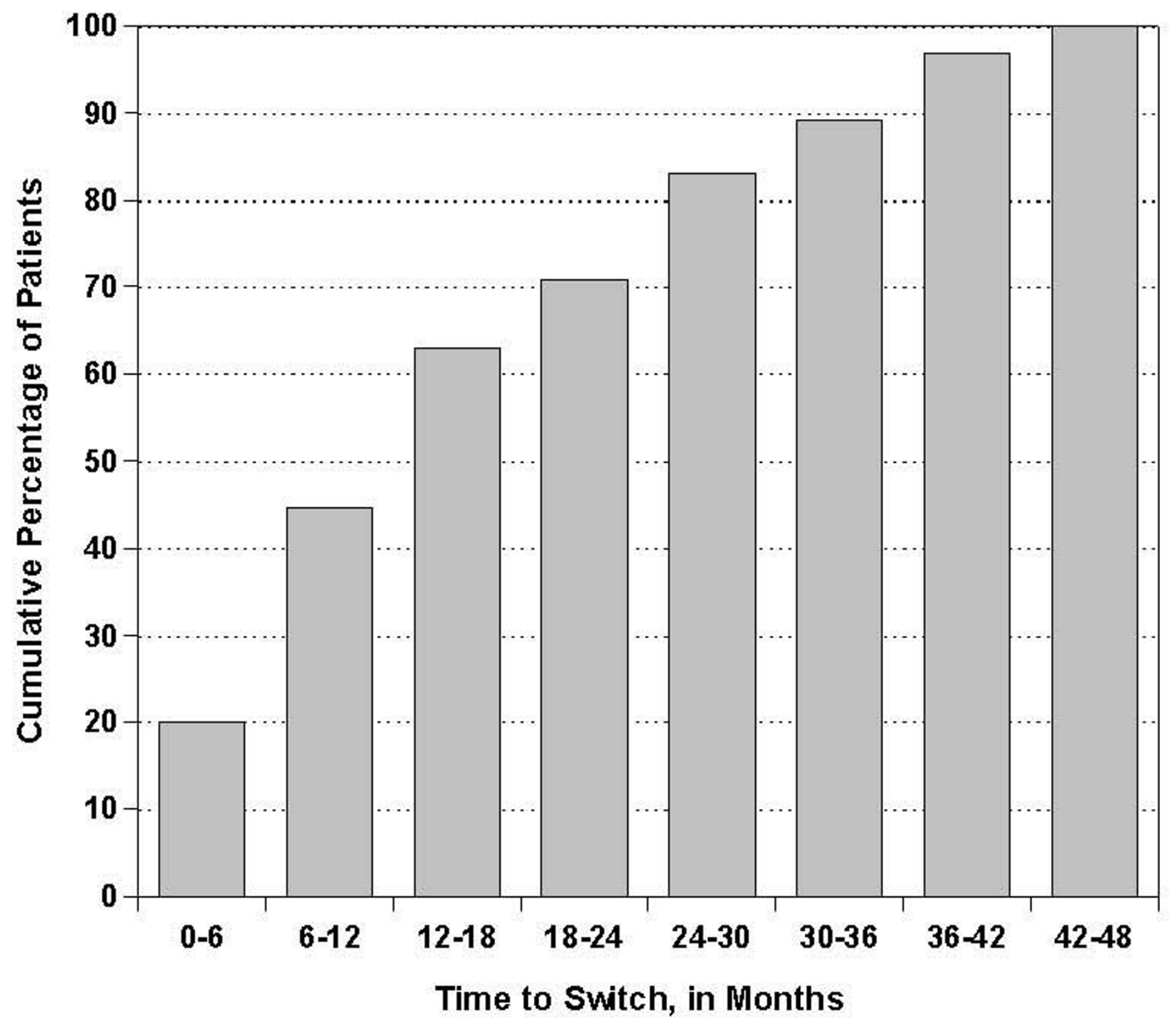

Figure I

Cumulative percentage of peritoneal dialysis patients by time from first dialysis to first switch to hemodialysis (switchers only).

ative Study on the Adequacy of Dialysis, 3-year technique survival was only $53 \%$ [21]. In a more recent U.S. cohort, Guo et al. [17] showed a significant trend towards decreasing transfer rates to HD during the first year on PD, from $19.6 \%$ in 1999 to $17.2 \%$ in 2001.

In agreement with previous studies, we found that infections remain the leading cause of switching from PD to HD, followed by cardiovascular causes, mainly fluid overload $[9,17,23]$. Infectious causes, which are generally preventable, were responsible for $28 \%$ of the transfers from PD to HD in a recent study by Mujais et al. [24]. However, in the early 1990s, this cause of dialysis modality transfer from PD to HD was reported to be as high as $49 \%$ [25]. Over the past few years, the use of the twin-bag and Y-set systems has certainly helped to decrease the peritonitis rate [26]. Ultrafiltration failure, leading to fluid overload, which was the next most important cause of transfer from PD to HD in our study, has been shown to increase with time on PD $[23,27]$; however, in our cohort, this trend was observed only during the first 18 months. We did not find an increasing number of ultrafiltration failures in our PD patients, possibly because a much smaller number of patients switched from PD to HD after 2 years. This ultra- 


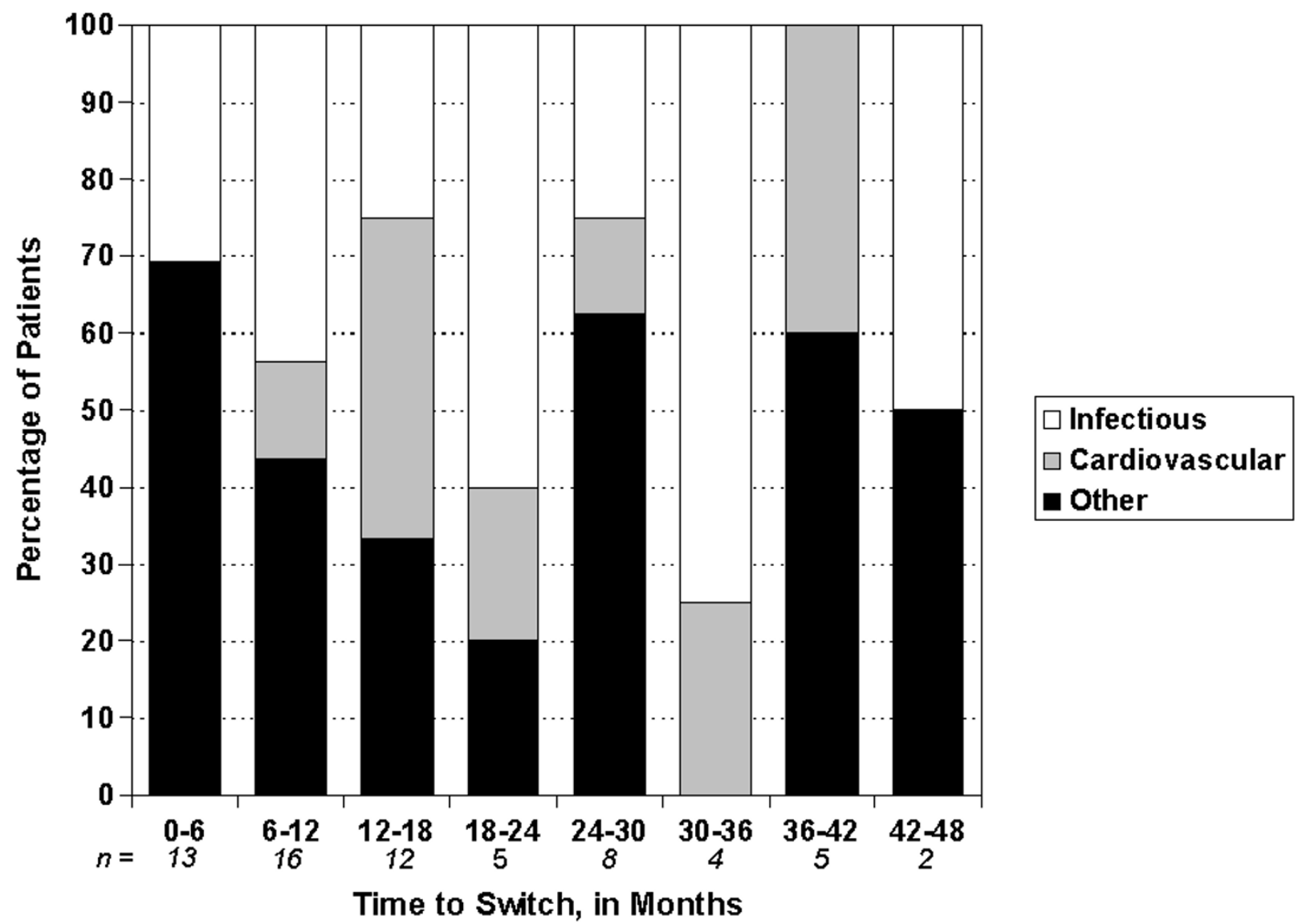

Figure 2

Percentage of switching peritoneal dialysis patients by main causes of switch and by time from first peritoneal dialysis to hemodialysis switch.

filtration failure is a consequence of morphological and functional changes of the peritoneal membrane, including increased small solute transport and lymphatic absorption, over time $[28,29]$. Loss of residual renal function with decreasing urine output observed over time in this cohort is also another likely mechanism leading to more fluid overload as a cause of transfer from PD to HD.

We identified several patient characteristics associated with a higher risk of switching from PD to HD over time. Patients of black race were 5 times more likely than white patients to switch from PD to HD. This finding is in accordance with an older single-center study, which reported a significantly higher technique failure rate in black patients (39\%) compared to white patients $(8 \%)$ [30]. Patients with diabetes mellitus have also been reported to have a higher transfer rate from $\mathrm{PD}$ to $\mathrm{HD}$ in some cohorts $[17,24]$ but certainly not all [31,32]. Similar to Huisman et al. [31] and Viglino et al. [32], we found no significant association between diabetes mellitus and modality transfer from PD to HD, although, in our cohort, more patients with diabetes mellitus switched to HD $(28.2 \%)$ compared to nondiabetics $(21.3 \%)$. This lack of statistical significance could be due to our smaller sample size. Parallel to previous studies, we found no effect of age on transfer rate from PD to HD [17], suggesting that PD can be performed in any age group with appropriate support.

There are little data looking at the association of BMI with technique survival among PD patients. In our study, higher BMI was independently associated with increasing risk of switching from PD to HD. This is in concordance with a recent retrospective cohort study [33] and another study from Australia and New Zealand, in which PD technique failure was $17 \%$ higher in obese patients compared to patients with normal BMI [34]. Peritoneal dialysis patients with higher BMI may be at increased risk for not 
Table 3: Predictors of dialysis modality switching: relative hazards for switching versus non-switching (time to first switch) from peritoneal dialysis to hemodialysis

\begin{tabular}{|c|c|c|}
\hline \multirow[b]{2}{*}{ Predictors } & \multicolumn{2}{|c|}{ Relative Hazards $(95 \% \mathrm{Cl})$} \\
\hline & Unadjusted & Adjusted* \\
\hline Age (per I-year increase) & $1.00(0.98-1.01)$ & $0.98(0.95-1.01)$ \\
\hline \multicolumn{3}{|l|}{ Race } \\
\hline White & 1.00 (ref.) & 1.00 (ref.) \\
\hline Black & $2.79(1.25-6.23)$ & $5.01(1.15-21.8)$ \\
\hline \multicolumn{3}{|l|}{ Education } \\
\hline High school graduate or higher & 1.00 (ref.) & 1.00 (ref.) \\
\hline Less than high school graduate & $1.64(0.83-3.23)$ & $2.53(0.98-6.55)$ \\
\hline \multicolumn{3}{|l|}{ Employment } \\
\hline Employed & I.00 (ref.) & $\mathrm{I} .00$ (ref.) \\
\hline Not employed & $1.5 \mathrm{I}(0.76-3.0 \mathrm{I})$ & $1.81(0.66-4.94)$ \\
\hline \multicolumn{3}{|l|}{ Distance to dialysis clinic } \\
\hline Living less than 30 miles from clinic & 1.00 (ref.) & 1.00 (ref.) \\
\hline Living 30 miles or more from clinic & $0.65(0.32-1.30)$ & $0.42(0.17-1.02)$ \\
\hline \multicolumn{3}{|l|}{ Diabetes } \\
\hline Nondiabetic & 1.00 (ref.) & $\mathrm{I} .00$ (ref.) \\
\hline Diabetic & $1.22(0.7 \mid-2.12)$ & $1.79(0.74-4.33)$ \\
\hline BMI (per I kg/m² increase) & $1.10(1.04-1.15)$ & $1.09(1.03-1.16)$ \\
\hline Baseline creatinine (per I mg/dl increase) & $1.13(1.02-1.26)$ & $1.13(0.97-1.33)$ \\
\hline
\end{tabular}

Number (\%) of patients switching/total number of patients by subpopulation: white, 47/212 (22.2\%); black, 18/50 (36.0\%); employed, 13/69 (18.8\%); not employed, 52/193 (26.9\%); high school graduate, $46 / 184$ (25.0\%); not high school graduate, I5/4I (36.6\%); nondiabetic, $27 / 127$ (21.3\%); diabetic, $38 / I 35$ (28.2\%); living at least 30 miles from dialysis clinic 4 I/I 55 (26.5\%); living less than 30 miles from dialysis clinic I6/6I (26.2\%).

* Adjusted model $(n=195)$ included age, race, education, employment, distance to dialysis clinic, diabetes mellitus status, BMI, baseline serum creatinine.

only infectious complications and inadequate dialysis but also peritoneal leaks because of raised intra-abdominal pressure [35,36]. Although in our study there was a clear trend towards a lower risk of transfer from PD to HD for patients living 30 miles or more from their dialysis clinic, this association was not statistically significant. However, a recent report from Canada clearly showed a significant trend toward decreasing PD technique failure with increasing distance from their nephrologist [37].
The impact of dialysis modality switching from PD to HD on patient survival remains controversial. We found no significant difference in survival over time between PD patients who switched to HD compared to those who remained on PD. Similar results have been reported in black patients in the United States [38] and in European cohorts [7]. However, other studies have shown higher mortality for PD patients who switched to HD compared to those who remained on PD $[9,19]$. In contrast to these 
Table 4: Risk of mortality associated with switching from peritoneal dialysis to hemodialysis: relative hazards for mortality for switchers vs. non-switchers

\begin{tabular}{|c|c|c|}
\hline \multirow[b]{2}{*}{ Model } & \multicolumn{2}{|c|}{ Relative Hazard $(95 \% \mathrm{Cl})$} \\
\hline & Non-switchers & Switchers \\
\hline No. of deaths/total no. of patients & $62 / 197$ & $26 / 65$ \\
\hline Incidence rate, per 100 patient-years & 18.5 & 13.5 \\
\hline Unadjusted & 1.00 (ref.) & $0.94(0.5 I-1.73)$ \\
\hline \multicolumn{3}{|l|}{ Adjusted } \\
\hline Model I (Demographics) & 1.00 (ref.) & $0.87(0.46-1.66)$ \\
\hline Model 2 (Model I + Clinical) & $\mathrm{I} .00$ (ref.) & $0.68(0.33-1.40)$ \\
\hline Model 3 (Model 2 + Laboratory) & $\mathrm{I} .00$ (ref.) & $0.89(0.41-1.93)$ \\
\hline
\end{tabular}

In these analyses, all patients start as non-switchers; if the patient switched modality the patient then became a switcher on the date of switch. *Demographics: age, race, employment; clinical: ICED, diabetes, CVD, BMI, residual urine output; laboratory: baseline albumin and creatinine. Fully adjusted models included all these variables.

reports, Van Biesen et al. [39], found a much better prognosis for PD patients who switched to HD compared to those remaining on PD. These differences in outcomes may be explained by differences in case-mix and reasons for technique failure. Several of these studies, including our own, showed that PD technique failure does not necessarily indicate worse prognosis after switching to HD; rather, more importantly, a timely transfer is vital when severe PD-related complications occur [40].

There are some limitations associated with our study. We had some, but not detailed, data on residual urine output. Furthermore, we had no data on peritoneal membrane characteristics; high peritoneal solute transport has been associated with PD technique failure and mortality in observational studies $[23,41]$ but not in a more recent prospective, randomized, controlled trial [42]. Also, because of the relatively smaller sample size, we combined automated PD and continuous ambulatory PD. But recently, Mujais et al. [24], using data from the Baxter Healthcare Corporation On-Call system reported that transfer to HD was lower in patients on automated PD than in patients on continuous ambulatory PD. However, compared to administrative data, our study provided the advantage of a prospective incident cohort with detailed data on comorbidities, laboratory values, and access to patient charts to determine specific causes of switching. There was a notable rate of lost to follow-up; however, mortality results including passive follow-up were similar to those without passive follow-up. Despite these limita- tions, our study represents, to our knowledge, one of the few prospective incident cohort studies specifically in the United States analyzing in detail switching of incident PD patients to HD, in terms of rate, timing, predictors and prognosis.

\section{Conclusion}

This prospective study of incident PD patients in the United States confirmed that the observed early switching rate from $\mathrm{PD}$ to HD remains too high and certainly represents a significant impediment to the long-term viability of any PD program. Additional efforts are urgently needed to continue to prevent PD-related infections, the leading cause of PD technique failure; also, when antibiotic response for peritonitis remains inadequate, early Tenckhoff catheter removal may help preserve the peritoneal membrane for future return to PD [43]. Moreover, we were able to identify important independent risk factors for switching from PD to HD (BMI and black race). In this context, more studies are definitely needed to better understand why black PD patients were more likely to switch to HD over time. Finally, our findings of no survival difference between PD switchers and non-switchers should be reassuring to providers and patients that PD technique failure is not necessarily associated with poor prognosis, but a timely transfer in setting of complications remains important.

\section{Competing interests}

The authors declare that they have no competing interests. 


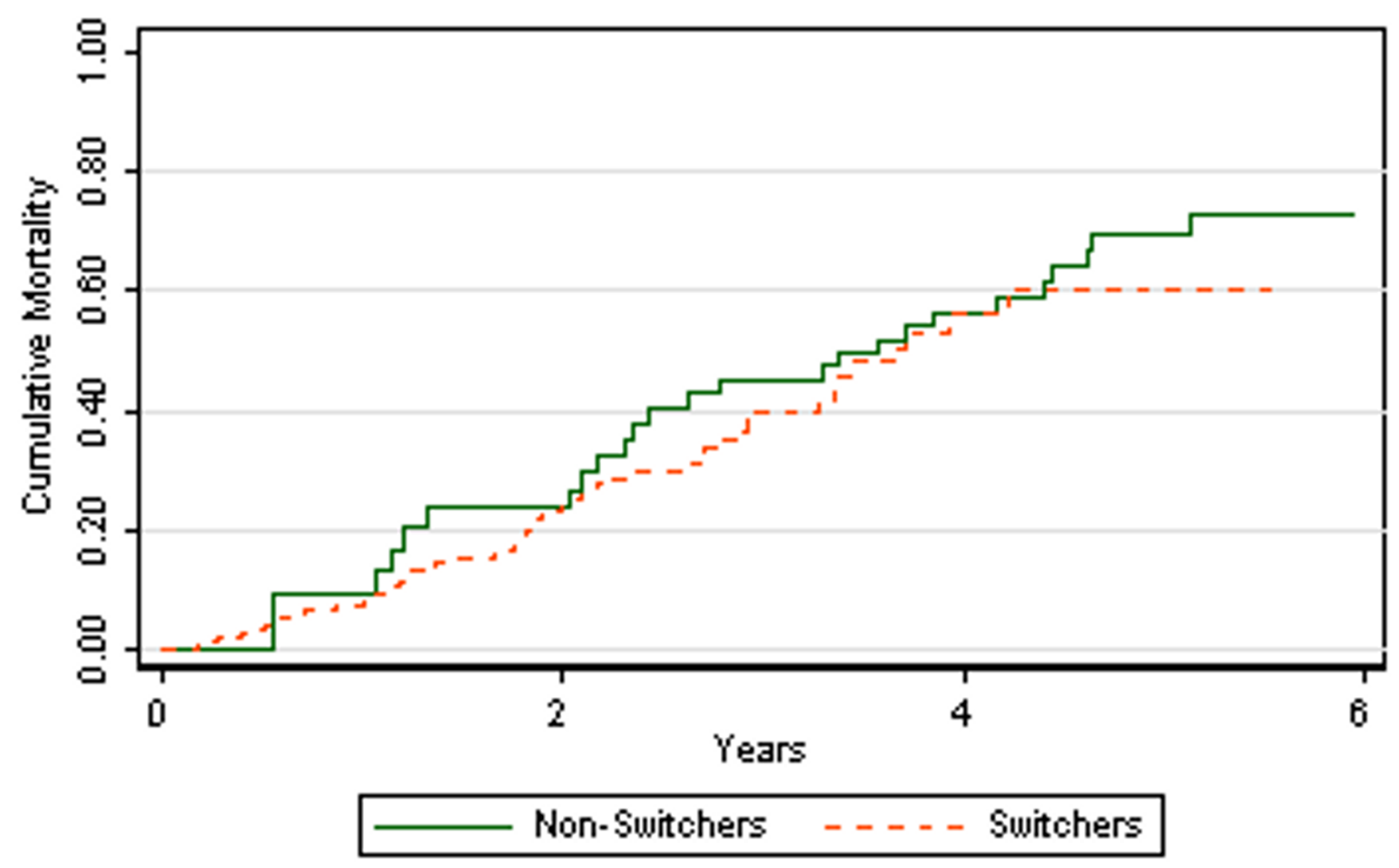

Figure 3

Kaplan-Meier curve for mortality, peritoneal dialysis switchers versus non-switchers $(P=0.528$ by log-rank).

\section{Authors' contributions}

BGJ analyzed and interpreted the data, reviewed medical records for causes of switching from peritoneal dialysis to hemodialysis, drafted and revised the manuscript for important intellectual content. LCP performed the statistical analysis, analyzed and interpreted the data, and revised the manuscript for important intellectual content. DCC reviewed medical records for causes of switching from peritoneal dialysis to hemodialysis and revised the manuscript for important intellectual content. NEF conceived and designed the study, obtained the data and revised the manuscript for important intellectual content. $\mathrm{NH}$ was involved in the provision of study patients and revised the manuscript for important intellectual content. JC conceived and designed the study, obtained the data, obtained funding, supervised the study, and revised the manuscript for important intellectual content. ASK was involved in the provision of study patients and revised the manuscript for important intellectual content. NRP conceived and designed the study, obtained the data, analyzed and interpreted the data, obtained funding, supervised the study, and revised the manuscript for important intellectual content. All authors read and approved the final manuscript.

\section{Acknowledgements}

We thank the patients, staff, and medical directors of the participating clinics at Dialysis Clinic, Inc., New Haven CAPD and St. Raphael's Hospital who contributed to the study.

This work was supported by grant no. ROI DK 59616 from the National Institute of Diabetes and Digestive and Kidney Diseases, Bethesda, MD, grant no. R0I-HS-08365 from the Agency for Health Care Research and Quality, Rockville, Maryland, and grant no. ROI HL 62985 from the National Heart Lung and Blood Institute, Bethesda, MD. Dr. Crews is supported by Grant Number IKL2RR025006-0I from the National Center for Research Resources (NCRR), a component of the National Institutes of Health (NIH), and NIH Roadmap for Medical Research. Dr. Powe is supported by grant K24DK02643.

\section{References}

I. Wu AW, Fink NE, Marsh-Manzi JV, Meyer KB, Finkelstein FO, Chapman MM, Powe NR: Changes in Quality of Life during Hemodialysis and Peritoneal Dialysis Treatment: Generic and Disease Specific Measures. J Am Soc Nephrol 2004, 1 5:743-753.

2. Rubin HR, Fink NE, Plantinga LC, Sadler JH, Kliger AS, Powe NR: Patient Ratings of Dialysis Care With Peritoneal Dialysis vs Hemodialysis. JAMA 2004, 291:697-703.

3. U.S. Renal Data System, USRDS 2007 Annual Data Report: Atlas of End-Stage Renal Disease in the United States, National Institutes of Health, National Institute of Diabetes and Digestive and Kidney Diseases, Bethesda, MD 2007.

4. Biesen Wv, Veys N, Lameire N, Vanholder R: Why less success of the peritoneal dialysis programmes in Europe? Nephrol Dial Transplant 2008, 23:1478-|48I. 
5. Gokal R, King J, Bogle S, Marsh F, Oliver D, Jakubowski C, Hunt L, Baillod R, Ogg C, Ward M, Wilkinson R: Outcome in patients on continuous ambulatory peritoneal dialysis and haemodialysis: 4-year analysis of a prospective multicentre study. The Lancet 1987, 330: I 105-I I09.

6. Serkes KD, Blagg CR, Nolph KD, Vonesh EF, Shapiro F: Comparison of patient and technique survival in continuous ambulatory peritoneal dialysis (CAPD) and hemodialysis: a multicenter study. Perit Dial Int 1990, 10:15-19.

7. Maiorca R, Cancarini GC, Zubani R, Camerini C, Manili L, Brunori G, Movilli E: CAPD viability: a long-term comparison with hemodialysis. Perit Dial Int 1996, 16:276-287.

8. Churchill DN, Thorpe KE, Vonesh EF, Keshaviah PR: Lower probability of patient survival with continuous peritoneal dialysis in the United States compared with Canada. Canada-USA (CANUSA) Peritoneal Dialysis Study Group. J Am Soc Nephrol |997, 8:965-97|.

9. Woodrow G, Turney JH, Brownjohn AM: Technique failure in peritoneal dialysis and its impact on patient survival. Perit Dial Int 1997, 17:360-364.

10. Szeto CC, Chow KM, Wong TY-H, Leung CB, Wang AY-M, Lui SF, Li PK: Feasibility of Resuming Peritoneal Dialysis after Severe Peritonitis and Tenckhoff Catheter Removal. J Am Soc Nephrol 2002, 13:1040-1045

11. Powe NR, Klag MJ, Sadler JH, Anderson GF, Bass EB, Briggs WA, Fink NE, Levey AS, Levin NW, Meyer KB, Rubin HR, Wu AW: Choices for healthy outcomes in caring for end stage renal disease. Semin Dial 1996, 9:9-II.

12. Kinchen KS, Sadler J, Fink N, Brookmeyer R, Klag MJ, Levey AS, Powe NR: The Timing of Specialist Evaluation in Chronic Kidney Disease and Mortality. Ann Intern Med 2002, I37:479-486.

13. Miskulin DC, Meyer KB, Athienites NV, Martin AA, Terrin N, Marsh JV, Fink NE, Coresh J, Powe NR, Klag MJ, Levey AS: Comorbidity and other factors associated with modality selection in incident dialysis patients: The CHOICE study. Am J Kidney Dis 2002, 39:324-336.

14. Athienites NV, Miskulin DC, Fernandez G, Bunnapradist S, Simon G, Landa M, Schmid CH, Greenfield S, Levey AS, Meyer KB: Comorbidity assessment in hemodialysis and peritoneal dialysis using the index of coexistent disease. Semin Dial 2000, 13:320-326.

15. Levey AS, Bosch JP, Lewis JB, Greene T, Rogers N, Roth D: A More Accurate Method To Estimate Glomerular Filtration Rate from Serum Creatinine: A New Prediction Equation. Ann Intern Med 1999, I30:46I-470.

16. Localio AR, Berlin JA, Ten Have TR, Kimmel SE: Adjustments for center in multicenter studies: an overview. Ann Intern Med 2001, 135:112-123.

17. Guo A, Mujais S: Patient and technique survival on peritoneal dialysis in the United States: Evaluation in large incident cohorts. Kidney Int 2003, 64:S3-SI2.

18. Jaar BG, Coresh J, Plantinga LC, Fink NE, Klag MJ, Levey AS, Levin NW, Sadler JH, Kliger A, Powe NR: Comparing the Risk for Death with Peritoneal Dialysis and Hemodialysis in a National Cohort of Patients with Chronic Kidney Disease. Ann Intern Med 2005, I 43: 174-183.

19. Schaubel DE, Blake PG, Fenton SS: Trends in CAPD technique failure: Canada, 198I-1997. Perit Dial Int 200I, $21: 365-37$ I.

20. Foley RN, Parfrey PS, Harnett JD, Kent GM, O'Dea R, Murray DC, Barre PE: Mode of dialysis therapy and mortality in end-stage renal disease. J Am Soc Nephrol 1998, 9:267-276.

21. Jager KJ, Merkus MP, Dekker FW, Boeschoten EW, Tijssen JGP, Stevens $P$, Bos WJ, Krediet RT: Mortality and technique failure in patients starting chronic peritoneal dialysis: Results of the Netherlands Cooperative Study on the Adequacy of Dialysis. Kidney Int 1999, 55: 1476-I 485.

22. Abbott KC, Glanton CW, Trespalacios FC, Oliver DK, Ortiz MI, Agodoa LY, Cruess DF, Kimmel PL: Body mass index, dialysis modality, and survival: Analysis of the United States Renal Data System Dialysis Morbidity and Mortality Wave II Study. Kidney Int 2004, 65:597-605.

23. Davies SJ, Phillips L, Griffiths AM, Russell LH, Naish PF, Russell GI: What really happens to people on long-term peritoneal dialysis? Kidney lnt 1998, 54:2207-2217.

24. Mujais S, Story K: Peritoneal dialysis in the US: Evaluation of outcomes in contemporary cohorts. Kidney Int Suppl 2006, 70:S2I-S26.
25. Maiorca R, Vonesh EF, Cavalli P, De Vecchi A, Giangrande A, La Greca G, Scarpioni LL, Bragantini L, Cancarini GC, Cantaluppi A, Castelnovo $C$, Castiglioni A, Poisetti P, Viglino G: A multicenter, selectionadjusted comparison of patient and technique survivals on CAPD and hemodialysis. Perit Dial Int 1991, I I:II8-127.

26. Strippoli GFM, Tong A, Johnson D, Schena FP, Craig JC: CatheterRelated Interventions to Prevent Peritonitis in Peritoneal Dialysis: A Systematic Review of Randomized, Controlled Trials. J Am Soc Nephrol 2004, 15:2735-2746.

27. Kawaguchi $Y$, Hasegawa T, Nakayama M, Kubo H, Shigematu $T$ : Issues affecting the longevity of the continuous peritoneal dialysis therapy. Kidney Int Suppl 1997, 62:SI05-SI07.

28. Fusshoeller A: Histomorphological and functional changes of the peritoneal membrane during long-term peritoneal dialysis. Pediatric Nephrology 2008, 23:19-25.

29. Fusshöller A, zur Nieden S, Grabensee B, Plum J: Peritoneal Fluid and Solute Transport: Influence of Treatment Time, Peritoneal Dialysis Modality, and Peritonitis Incidence. J Am Soc Nephrol 2002, 13:1055-1060.

30. Korbet SM, Shih D, Cline KM, Vonesh EF: Racial differences in survival in an urban peritoneal dialysis program. Am J Kidney Dis 1999, 34:7I3-720.

31. Huisman RM, Nieuwenhuizen MGM, de Charro FT: Patient-related and centre-related factors influencing technique survival of peritoneal dialysis in The Netherlands. Nephrol Dial Transplant 2002, 17:1655-1660.

32. Viglino G, Cancarini GC, Catizone L, Cocchi R, De Vecchi A, Lupo A, Salomone M, Segoloni GP, Giangrande A: Ten years experience of CAPD in diabetics: comparison of results with non-diabetics. Nephrol Dial Transplant 1994, 9: I 443-I 448.

33. Snyder J], Foley RN, Gilbertson DT, Vonesh EF, Collins AJ: Body size and outcomes on peritoneal dialysis in the United States. Kidney Int 2003, 64: 1838-I844.

34. McDonald SP, Collins JF, Johnson DW: Obesity Is Associated with Worse Peritoneal Dialysis Outcomes in the Australia and New Zealand Patient Populations. J Am Soc Nephrol 2003, I 4:2894-290I.

35. Schmekal B: Peritoneal dialysis in patients with high bodymass index. Wiener Klinische Wochenschrift 2005, I I 7:40-45.

36. McDonald SP, Collins JF, Rumpsfeld M, Johnson DW: Obesity is a risk factor for peritonitis in the Australian and New Zealand peritoneal dialysis patient populations. Perit Dial Int 2004, 24:340-346

37. Tonelli M, Hemmelgarn B, Culleton B, Klarenbach S, Gill JS, Wiebe N, Manns B, Alberta Kidney Disease Network: Mortality of Canadians treated by peritoneal dialysis in remote locations. Kidney Int 2007, 72: 1023-1028.

38. Kim GC, Vonesh EF, Korbet SM: The effect of technique failure on outcome in black patients on continuous ambulatory peritoneal dialysis. Perit Dial Int 2002, 22:53-59.

39. Van Biesen W, Dequidt C, Vijt D, Vanholder R, Lameire N: Analysis of the reasons for transfers between hemodialysis and peritoneal dialysis and their effect on survivals. Adv Perit Dial 1998 , 14:90-94.

40. Van Biesen W, Vanholder RC, Veys N, Dhondt A, Lameire NH: An evaluation of an integrative care approach for end-stage renal disease patients. J Am Soc Nephrol 2000, I I: I I 6- 125.

4I. Churchill DN, Thorpe KE, Nolph KD, Keshaviah PR, Oreopoulos DG, Page D: Increased peritoneal membrane transport is associated with decreased patient and technique survival for continuous peritoneal dialysis patients. The Canada-USA (CANUSA) Peritoneal Dialysis Study Group. J Am Soc Nephrol 1998, 9:1285-1292.

42. Paniagua R, Amato D, Vonesh E, Correa-Rotter R, Ramos A, Moran J, Mujais S, Mexican Nephrology Collaborative Study Group: Effects of Increased Peritoneal Clearances on Mortality Rates in Peritoneal Dialysis: ADEMEX, a Prospective, Randomized, Controlled Trial. J Am Soc Nephrol 2002, I 3: I $307-1320$

43. Szeto CC, Chow KM, Leung CB, Wong TY, Wu AK, Wang AY, Lui SF, Li PK: Clinical course of peritonitis due to Pseudomonas species complicating peritoneal dialysis: A review of 104 cases. Kidney Int 200I, 59:2309-23I 5. 


\section{Pre-publication history}

The pre-publication history for this paper can be accessed here:

http://www.biomedcentral.com/1471-2369/10/3/prepub

Publish with Bio Med Central and every scientist can read your work free of charge

"BioMed Central will be the most significant development for disseminating the results of biomedical research in our lifetime. " Sir Paul Nurse, Cancer Research UK

Your research papers will be:

- available free of charge to the entire biomedical community

- peer reviewed and published immediately upon acceptance

- cited in PubMed and archived on PubMed Central

- yours - you keep the copyright
BioMedcentral 